\title{
Vestibular Signals in Primate Thalamus: Properties and Origins
}

\author{
Hui Meng, ${ }^{1}$ Paul J. May, ${ }^{2}$ J. David Dickman, ${ }^{1}$ and Dora E. Angelaki ${ }^{1}$ \\ ${ }^{1}$ Department of Anatomy and Neurobiology, Washington University School of Medicine, St. Louis, Missouri 63110, and 2Departments of Anatomy, \\ Ophthalmology and Neurology, University of Mississippi Medical Center, Jackson, Mississippi 39216
}

\begin{abstract}
Vestibular activation is found in diverse cortical areas. To characterize the pathways and types of signals supplied to cortex, we recorded responses to rotational and/or translational stimuli in the macaque thalamus. Few cells responded to rotation alone, with most showing convergence between semicircular canal and otolith signals. During sinusoidal rotation, thalamic responses lead head velocity by $\sim 30^{\circ}$ on average at frequencies between $0.01-4 \mathrm{~Hz}$. During translation, neurons encoded combinations of linear acceleration and velocity. In general, thalamic responses were similar to those recorded in the vestibular and cerebellar nuclei using identical testing paradigms, but differed from those of vestibular afferents. Thalamic responses represented a biased continuum: most cells more strongly encoded translation and fewer cells modulated primarily in response to net gravitoinertial acceleration. Responsive neurons were scattered within a large area that included regions of the ventral posterior and ventral lateral nuclei, and so were not restricted to the known vestibular nuclei projection zones. To determine the origins of these responses, a retrograde tracer was injected into a dorsolateral thalamic site where rotation/translation-sensitive cells were encountered. This injection labeled neurons in the rostral contralateral anterior interposed and fastigial nuclei, but did not label cells within the vestibular nuclei. Examination of thalamic terminations after tracer injections into the cerebellar and vestibular nuclei indicated that most vestibular responsive units fall within the thalamic terminal zones of these nuclei. Thus, vestibular signals, which are supplied to the thalamus from both vestibular and cerebellar nuclei, are positioned for distribution to widespread cortical areas.
\end{abstract}

Key words: sensorimotor; thalamocortical; cerebellar nuclei; vestibular nuclei; translation; semicircular canals; motion; otolith organs

\section{Introduction}

Compared with other sensory systems, little is currently known about the properties and functions of the vestibular thalamus or the neuroanatomical pathways by which vestibular information reaches the cortex. Widespread, bilateral thalamic projections from the vestibular nuclei (VN) have been reported in the rat (Nagata, 1986; Shiroyama et al., 1995, 1999) and cat (Kotchabhakdi et al., 1980; Maciewicz et al., 1982; Nakano et al., 1985). However, the projection in primates appears to be more discrete. It is organized into small patches, within the ventral tier, particularly along the border between the ventral posterior lateral (VPL) and ventral lateral nuclei (VL) (Lang et al., 1979; Asanuma et al., 1983). Thalamic neurons in this region are activated by vestibular nerve stimulation (Liedgren et al., 1976; Meng et al., 2001) and project to areas of cerebral cortex that respond to vestibular stimuli (Akbarian et al., 1992).

Neurons in the fastigial and anterior interposed nuclei also modulate their firing rates during vestibular stimulation (Gardner and Fuchs, 1975; Büttner et al., 1991; Siebold et al., 1997;

Received Aug. 28, 2007; revised 0ct. 3, 2007; accepted 0ct. 22, 2007.

This work was supported by National Institutes of Health Grant R01-DC04260.

Correspondence should be addressed to Dr. Dora E. Angelaki, Department of Anatomy and Neurobiology, Box 8108, Washington University School of Medicine, 660 South Euclid Avenue, St. Louis, M0 63110. E-mail: angelaki@pcg.wustl.edu.

DOI:10.1523/JNEUROSCI.3931-07.2007

Copyright $\odot 2007$ Society for Neuroscience $\quad$ 0270-6474/07/2713590-13\$15.00/0
Zhou et al., 2001; Shaikh et al., 2004, 2005a,b). Furthermore, neuroanatomical studies have clearly shown cerebellar nuclei (CN) projections to the thalamus, particularly to the VL (Stanton, 1980; Asanuma et al., 1983; Thach, 1987; Sakai et al., 1996; Middleton and Strick, 1997). Consequently, cerebellothalamic projections may provide an additional route for vestibular information to the thalamus. This possibility has not been explored previously.

To date, few studies have been undertaken to describe primate thalamic neuron responses in awake behaving animals during natural vestibular stimulation (Büttner and Henn, 1976; Büttner et al., 1977; Magnin and Fuchs, 1977). These studies, which were limited to yaw plane stimulation, reported that yaw response dynamics of thalamic neurons are similar to those in VN (Büttner et al., 1977). More recently, the response properties of $\mathrm{VN}$ and $\mathrm{CN}$ neurons have been characterized in detail using translations and rotations about multiple axes (Dickman and Angelaki, 2002; Angelaki et al., 2004; Shaikh et al., 2005a,b; Chen-Huang and Peterson, 2006; Yakushin et al., 2006). It remains to be determined whether the similarity between brainstem and thalamic response properties extends beyond yaw rotation.

The main goal of this study was to characterize thalamic response properties during rotation, translation and combination stimuli so that direct comparisons to the responses of previously characterized VN and CN neurons could be made (Angelaki et al., 2004; Dickman and Angelaki, 2002, 2004; Shaikh et al., 
2005a,b). This information will yield a basic understanding of thalamic neural processing of vestibular signals, and provide insight into previous advances regarding cortical use of vestibular information (Fukushima et al., 2000, 2004; Chen et al., 2006, 2007; Gu et al., 2006, 2007). In addition, we investigated the anatomical origin of these responses by injecting neuroanatomical tracers into a vestibular responsive region of the thalamus and into its putative sources of input: the VN and CN. Preliminary aspects of this work have been presented in abstract form (Meng et al., 2006).

\section{Materials and Methods}

Animals and experimental setup. The physiology experiments were performed in two alert juvenile Macacca mulatta monkeys. The animals were chronically implanted with a delrin ring to restrain head movement during experiments. A neural recording platform with predrilled holes spaced $0.8 \mathrm{~mm}$ apart was secured stereotaxically within the headrestraining ring by use of dental cement. The recording platform allowed electrode penetrations to cover areas of the thalamus bilaterally. Search coils were also chronically implanted for measuring eye movements (for details, see Angelaki et al., 2000, 2001; Meng et al., 2005). The surgical and experimental procedures conformed to the National Institutes of Health guidelines and were approved by the Animal Care and Use Committee at Washington University.

Animals were seated comfortably in a primate chair that was mounted inside a vestibular turntable (Acutronics, Pittsburgh, PA). The turntable delivered rotations in three dimensions (yaw, pitch, and roll) and translations (on a $2 \mathrm{~m}$ sled) along any direction in the earth-horizontal plane. The position of the animal inside the primate chair was adjusted such that (1) the rotation axes passed through the center of the head, along the interaural line and (2) the horizontal stereotaxic plane was parallel with the earth-horizontal during experiments. Visual targets for evoking saccadic and pursuit eye movements were delivered using a laser $/ x-y$ mirror galvanometer system (GSI Lumonics, Moorpark, CA), with the laser beam back projected onto a screen placed $33 \mathrm{~cm}$ away. We monitored the animal's motion using the output of a three-dimensional accelerometer that was mounted on the inner frame of the turntable, as well as velocity and position feedback signals from the rotators. These signals, as well as eye coil voltages, were filtered $(200 \mathrm{~Hz}, 6$ pole Bessel), digitized at a rate of $833.33 \mathrm{~Hz}$, and stored on a personal computer (PC) for off-line analysis. Stimulus delivery and data acquisition were controlled with customwritten scripts for the Spike2 software environment by use of a Cambridge Electronics Design (Cambridge, UK) data acquisition interface (model power 1401, 16 bit resolution). Eye movement calibration procedures were similar to those in previous studies (Meng et al., 2005; Meng and Angelaki, 2006).

Neural recordings. Extracellular recordings from isolated single neurons were obtained with epoxy-coated tungsten microelectrodes ( 2 to 4 $\mathrm{M} \Omega$ impedance; FHC, Bowdoinham, ME). Each electrode reached the midbrain and thalamus through a 26 gauge cannula and was manipulated with a remote-controlled microdrive (FHC). Neural activity was amplified and filtered $(300 \mathrm{~Hz}-6 \mathrm{kHz})$. The action potentials were discriminated using a dual time-amplitude window discriminator (BAK, Germantown, MD), and used to trigger acceptance pulses that were stored on a PC through the event channel of the CED power 1401. In initial experiments performed in each monkey, the oculomotor nuclei and the rostral interstitial nucleus of medial longitudinal fasciculus (riMLF) were identified based on their characteristic firing patterns during pursuit and vertical saccadic eye movements. These two structures were then used as landmarks for guiding electrode penetrations into the thalamus. In particular, the riMLF, a small area ( $<2 \mathrm{~mm}$ across) whose cells burst selectively during vertical and torsional saccadic eye movements (Suzuki et al., 1995), is located just ventromedial to the ventral posterior complex (VP) and lies near the anterior/posterior level of the rostral border of VPL. This border region is the anatomical location of the vestibulothalamic projection zone (Lang et al., 1979).

As the electrode entered the thalamus, our search stimulus consisted of yaw/pitch rotation or lateral translation at a single frequency $(0.5 \mathrm{~Hz})$.
Once a thalamic cell was satisfactorily isolated, it was tested with $0.5 \mathrm{~Hz}$ sinusoidal rotation (yaw, pitch, and roll, $0.5 \mathrm{~Hz} \pm 10^{\circ}$ ) and translational movement (lateral and fore-aft, $0.5 \mathrm{~Hz} \pm 0.2 \mathrm{G}, \mathrm{G}=9.8 \mathrm{~m} / \mathrm{s}^{2}$ ), as well as with targets for visually guided saccade and horizontal/vertical pursuit eye movements. Only those rotation/translation-sensitive cells without any modulation during either slow or fast eye movements were included in this study, and received additional testing with motion stimuli at different frequencies. During yaw rotation, peak head velocity was kept constant at $31 \%$ for most frequencies $(0.01,0.02,0.05,0.1,0.25,0.5,1$ $\mathrm{Hz}$ ), but because of technical limitations this was reduced to $15^{\circ} / \mathrm{s}$ at $2 \mathrm{~Hz}$ and $7 \%$ at $4 \mathrm{~Hz}$. For translation, peak accelerations were $\sim 0.1 \mathrm{G}$ at 0.16 and $0.3 \mathrm{~Hz}, 0.2 \mathrm{G}$ at 0.5 and $1 \mathrm{~Hz}$, and $0.35 \mathrm{G}$ at 2, 4, and $5 \mathrm{~Hz}$. All vestibular response data were collected during motion in complete darkness.

If cell isolation was maintained, combinations of translational and rotational motion stimuli were also delivered in darkness. These stimuli were identical to those used previously to independently manipulate inertial and net gravitoinertial accelerations (Angelaki et al., 2004; Shaikh et al., 2005b; Yakusheva et al., 2007); they consisted of pure translation (translation), pure tilt (tilt), or combined translation and tilt (tilt minus translation motion and tilt plus translation). The tilt stimulus consisted of a $0.5 \mathrm{~Hz}$ sinusoidal rotation from an upright position with peak amplitude of $11.3^{\circ}\left(36^{\circ} \mathrm{s}\right)$. As this motion reorients the head relative to gravity, otolith afferents were stimulated by a linear acceleration component in the horizontal plane with a peak magnitude of $0.2 \mathrm{G}$. The amplitude of the translation stimulus was adjusted to match that induced by the head tilt $(0.2 \mathrm{G} \pm 20 \mathrm{~cm})$. During combined rotational and translational stimulation, the inertial and gravitational acceleration components combined in either an additive or subtractive manner, depending on the relative directions of the two stimuli. As a result, the net gravitoinertial acceleration in the horizontal plane either doubled (tilt plus translation), or was nearly zero (tilt minus translation), although the actual translation of the animal remained the same. By comparing cell responses under these conditions, one can ascertain whether the activity of thalamic neurons is modulated in response to translational motion alone or, like primary otolith afferents, to net gravitoinertial acceleration (Angelaki et al., 1999, 2004).

Each cell was usually characterized at a minimum of two orientations $\left(\theta=0^{\circ}\right.$ and $\left.\theta=90^{\circ}\right)$ corresponding to lateral motion/roll tilt and fore-aft motion/pitch tilt, respectively. Several cells were also tested along their best-responding direction at two different frequencies during these four protocols (translation, tilt, tilt minus translation, tilt plus translation): $0.16 \mathrm{~Hz}\left( \pm 0.1 \mathrm{G}\right.$, corresponding to tilt and translation amplitudes of $5.7^{\circ}$ and $95.6 \mathrm{~cm}$, respectively) and $1 \mathrm{~Hz}( \pm 0.087 \mathrm{G}$, corresponding to tilt and translation amplitudes of $5^{\circ}$ and $2.16 \mathrm{~cm}$, respectively). Many thalamic neurons also changed their firing rates in response to somatosensory stimuli, but because no systematic characterization was performed, our analyses focused exclusively on their responsiveness during rotational and/or translational motion in darkness. Because the animals' heads were fixed and their bodies confined, we believe that little systematic modulation caused by neck proprioception was present in the responses. Nevertheless, because we did not record in these areas after bilateral labyrinthectomy (Takahashi et al., 2007), we cannot exclude that some of the observed modulation arises at least partly from extralabyrinthine (e.g., somatosensory) signals.

Data analyses. Data analyses were performed off-line using Matlab (MathWorks, Natick, MA). Neural firing rate was calculated as the inverse of interspike interval. At least 10 response cycles were folded into a single cycle, and fitted by a sine function to determine response amplitude and phase (for details, see Meng et al., 2005; Meng and Angelaki 2006). Response amplitude refers to half the peak-to-trough modulation. Neural response gain for rotation was computed as the ratio of response amplitude and peak stimulus velocity (in units of spikes per second per degrees per second). Response phase for rotation was calculated as the difference between peak response and peak head velocity. For quantification of the frequency responses of thalamic neurons during translation, response gain and phase were expressed relative to linear acceleration. To characterize the response dynamics of thalamic neurons and compare them with those of brainstem and cerebellar neurons, we plot- 
ted neuronal gain (i.e., ratio of response amplitude over rotational velocity or linear acceleration) and phase as a function of frequency.

To determine whether the measured distribution of translational preferred directions was significantly different from uniform, we performed a resampling analysis. First, we calculated the sum squared error (across bins) between the measured distribution and an ideal uniform distribution containing the same number of observations. Next, we generated a random distribution by drawing the same number of data points from a uniform distribution using the "unifrnd" function in Matlab. The sum squared error was again calculated between this random distribution and the ideal uniform distribution. This second step was repeated 1000 times to generate a distribution of sum squared error values that represent random deviations from an ideal uniform distribution. If the sum squared error for the experimentally measured distribution lay outside the $95 \%$ confidence interval (CI) of values from the randomized distributions, then the measured distribution was considered to be significantly different from uniform $(p<0.05)$.

To determine whether each individual cell encoded translation or net linear acceleration, linear regression analyses were used to simultaneously fit the cumulative cycles of cell modulation during each of the translation, tilt and combined stimuli using "afferent-like" and "translation-coding" models. Briefly, these models assume that neural firing rate modulation is either attributable to the net acceleration or to the translational acceleration component (for details, see Angelaki et al., 2004; Green et al., 2005; Shaikh et al., 2005b; Yakusheva et al., 2007). How well each of these two models fitted the data were evaluated using a partial correlation analysis. The calculated partial correlation coefficients were subsequently converted to $z$-scores using Fisher's $r$-to- $z$ transform, to facilitate the interpretation of statistical significance independent of the number of data points (Angelaki et al., 2004; Smith et al., 2005). The advantage of this comparison is that when $z$-scores for one model are plotted versus the respective $z$-scores for the other model, the plot can be easily separated into regions in which data points can be distinguished as being better correlated with one model, compared with the other, at a particular level of significance.

In addition to these two models, we also fitted a third, "sensory convergence" model, which assumes that neural firing rates can be modeled as a linear combination of net acceleration, (sensed by the otoliths) and an internal estimate of gravity (derived from semicircular canal signals). Each of these terms contributed to neural firing rates with a weight, $k_{1}$ and $k_{2}$, respectively (note that $k_{1}$ and $k_{2}$ are complex coefficients associated with both amplitude and phase values) (Angelaki et al., 2004; Green et al., 2005).

Anatomical procedures. In one of the animals, wheatgerm agglutinin conjugated horseradish peroxidase (WGA-HRP) was injected into one of the locations at which motion-sensitive neurons were recorded. A $1.0 \mu \mathrm{l}$ syringe (Hamilton) was used to inject $0.2 \mu \mathrm{l}$ of a solution of $2.0 \%$ WGAHRP (Sigma, St. Louis, MO) at a physiologically defined depth after advancing the syringe through an extant guide tube. In addition to the WGA-HRP injection, two electrolytic lesions were also made within the region of vestibularly responsive cells to verify the penetration sites and allow more precise reconstruction of cell location. After a postinjection survival time of $48 \mathrm{~h}$, the animal was killed under sodium pentobarbital $(50 \mathrm{mg} / \mathrm{kg}$, i.v.) and perfused through the heart with a buffered saline prewash followed by a solution containing $1.0 \%$ paraformaldehyde and $1.25 \%$ glutaraldehyde in $0.1 \mathrm{M}, \mathrm{pH} 7.2$ phosphate buffer (PB). The brain was blocked in the frontal plane and removed. It was cryoprotected in $30 \%$ sucrose $\mathrm{PB}$, before being frozen and sectioned at a thickness of 80 $\mu \mathrm{m}$ on a sliding microtome. An ordered series of every third section was reacted to reveal the location of the HRP using the chromagen tetramethylbenzidine (TMB) (for detailed procedures, see Perkins et al., 2006; Olucha et al., 1985). Briefly, the sections were incubated in a solution containing $0.005 \% \mathrm{TMB}, 0.245 \%$ ammonium molybdate, and $0.25 \%$ ethanol in $0.1 \mathrm{M} \mathrm{PB}, \mathrm{pH}$ 6.0. The reaction was initiated by the addition of $0.011 \%$ hydrogen peroxide and ran for $18 \mathrm{~h}$ at $4^{\circ} \mathrm{C}$. The reaction product was stabilized by treatment in $5.0 \%$ ammonium molybdate in $0.1 \mathrm{M} \mathrm{PB}$, $\mathrm{pH}$ 6.0. Then the sections were mounted and counterstained with cresyl violet. One of the remaining one-in-three series was mounted and counterstained with cresyl violet, and the other was reacted to reveal the presence of cytochrome oxidase by use of the method of Wong-Riley (1979). These sections were used to reconstruct a recording map with respect to cytoarchitectonic boundaries.

For this animal, the location of each recorded cell was reconstructed according to the relationship between its recorded position (based on the predrilled recording grid hole and micromanipulator depth reading) and the location of the riMLF and the electrolytic lesions. The main nuclei in which vestibular units have been observed are found in the ventral tier: the VL and subdivisions of the VP, including the VPL, ventral posterior medial nucleus (VPM), and ventral posterior inferior (VPI) (Deecke et al., 1974, 1977; Büttner and Henn, 1976; Magnin and Fuchs, 1977; Büttner and Lang, 1979). Those investigating vestibular responses in the thalamus have subdivided these nuclei in numerous ways. In particular, Lang et al. (1979), who described VN inputs in the macaque thalamus, used the subdivisions of Olszewski (1952) and called the area receiving VN inputs the oral subdivision of VPL (VPLo). In contradistinction to the system of Olszewski (1952), in which the VPLo reaches far into the portion of thalamus that supplies cortical area 4, we have adopted a nomenclature and borders in line with the findings of Macchi and Jones (1997) (see also Steriade et al., 1997). These authorities reserve VPL to define the thalamic region receiving somatosensory information, and term the region dorsal and rostral to this, which supplies primary motor cortex, VL. VPL has been further subdivided into a core region responsible for tactile information and a shell region that receives proprioceptive information (Maendly et al., 1981; Hutchison et al., 1992; Steriade et al., 1997). A portion of the vestibular units recorded in thalamus fall into this shell region, and are interspersed with nonvestibular units, some of which receive proprioceptive inputs (Büttner and Henn, 1976; Deecke et al., 1977).

Previously, Akbarian et al. (1992), in their study of thalamic neurons that project to cortical areas with vestibular responses in squirrel monkeys, proposed additional subdivisions of VP: oralis, superior, and posterior, in which they find prospective vestibular thalamocortical neurons. These new subdivisions may be part of the VPL shell. We took a conservative approach, and did not attempt further subdivisions of VPL and VL. The atlases of Paxinos et al. (2000) and Saleem and Logothetis (2007) were used as a general guide for the anatomical and physiological components of this study. In addition, cases from our collection with dorsal column nuclei and trigeminal complex tracer injections were used to guide our placement of VPL and VPM borders. In this context, the region containing vestibulothalamic projections lies primarily in the rostral and dorsal VPL, and in adjacent parts of the VL.

Finally, to compare the location of thalamic neurons that have vestibular sensitivity with the terminal distribution of inputs from structures known to have vestibular responses and thalamic projections, we examined the thalamic projections after tracer was injected into the $\mathrm{VN}(n=$ $2)$ or the $\mathrm{CN}(n=3)$. The injection and reaction protocols for the illustrated cases were essentially the same as those detailed above. Our goal here is not to provide a detailed characterization of these projections, but rather a gross comparison between the thalamic regions with vestibularrelated activity and those receiving $\mathrm{CN}$ and $\mathrm{VN}$ inputs.

\section{Results}

Electrode penetrations into the thalamus were guided by the location of the oculomotor nuclei and the riMLF. One thousand three hundred and thirty-seven cells were isolated long enough to be tested with a battery of motion stimuli, including lateral and fore-aft translation, yaw, pitch and roll rotations, as well as horizontal/vertical smooth pursuit and saccadic eye movements. Of those cells, $1182(88.4 \%)$ did not modulate during rotation, translation or eye movements. An additional small proportion $(13,1 \%)$ exhibited eye movement sensitivity. The remaining cells $(142,10.6 \%)$ responded to at least one of the motion stimuli (but not during saccades, pursuit, or fixation) and have been included in this analysis.

Responses from a typical cell are shown in Figure 1. This neuron, like most thalamic vestibular cells, modulated its firing rate 


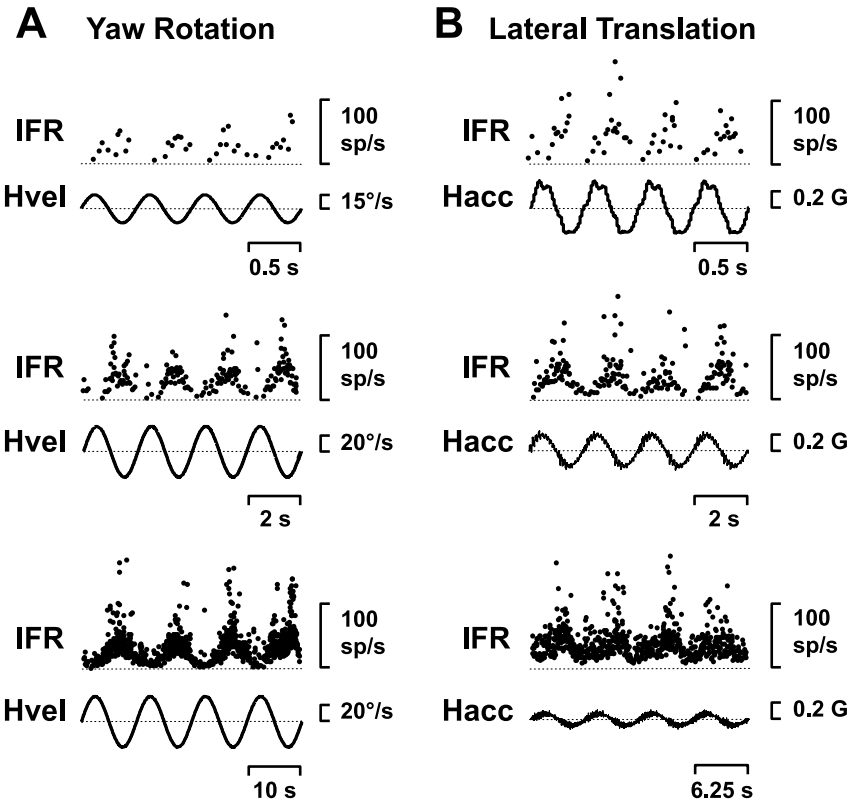

Figure 1. $\quad \boldsymbol{A}, \boldsymbol{B}$, Neural responses of a motion-sensitive thalamic neuron during yaw rotation $(\boldsymbol{A} ; 2 \mathrm{~Hz}, 0.5 \mathrm{~Hz}$ and $0.1 \mathrm{~Hz})$ and lateral translation $(\boldsymbol{B}, 2 \mathrm{~Hz}, 0.5 \mathrm{~Hz}$ and $0.16 \mathrm{~Hz})$. IFR, Instantaneous firing rate; Hvel, head velocity; Hacc, head linear acceleration; $s p$, spikes; $G=9.8 \mathrm{~m} / \mathrm{s}^{2}$.

during both yaw rotation and lateral translation (Fig. $1 A, B$, different rows plot responses at different frequencies). Of 80 cells that were tested with all four motion directions (i.e., yaw, pitch, lateral translation, and fore-aft translation), only five cells (6\%) were exclusively selective for rotation (i.e., they did not modulate during translation). Similarly, only 3 cells (4\%) responded during horizontal plane translation, but did not modulate during yaw, pitch, and roll rotations. In general, thalamic neurons had low spontaneous firing rates, with a mean $( \pm S D)$ of $47.4 \pm 22.7$ spikes/s (range: $10.4-119.6$ spikes/s) and coefficient of variation of $0.88 \pm 0.49$ (range: $0.35-2.39, n=56$ ). In the following description, we first examine the properties of thalamic neurons during yaw (earth-vertical axis) rotation and horizontal plane translation. This is followed by discussion of their response characteristics during earth-horizontal axis (pitch/roll) rotations, and combinations of tilt and translation. At the end of the Results section, we will describe the location of the recorded neurons and provide neuroanatomical evidence regarding the origins of vestibular responsiveness in the primate thalamus.

\section{Response properties during yaw rotation}

Twenty nine motion-sensitive neurons responded during yaw rotation (Fig. 2). At $0.5 \mathrm{~Hz}$, yaw rotational gains averaged $0.53 \pm$ 0.27 (range, $0.21-1.24$ ). Figure $2 A$ plots neuronal response gain (expressed in spikes per second per degree per second) and phase (expressed relative to head velocity) from individual cells as a function of stimulus frequency. Response dynamics were similar for rotation only neurons (5 of 29) (Fig. $2 A$, open squares) and rotation plus translation neurons (24 of 29) (Fig. $2 A$, filled squares) (ANOVA with repeated measures, $F_{(1,4)}=0.079 ; p=$ $0.79)$. Notably, response phase (expressed in the interval $\left[-90^{\circ}\right.$, $\left.90^{\circ}\right]$ ) varied considerably among thalamic neurons. Figure $2 B$ shows the corresponding mean gain and phase $( \pm S D)$ across the population. Because not all cells were tested at all frequencies (but all were tested at $0.5 \mathrm{~Hz}$ ), and neural response gain varied from cell to cell, gains at all frequencies for each cell were normalized by dividing with the respective gain at $0.5 \mathrm{~Hz}$. Thus, the normal-
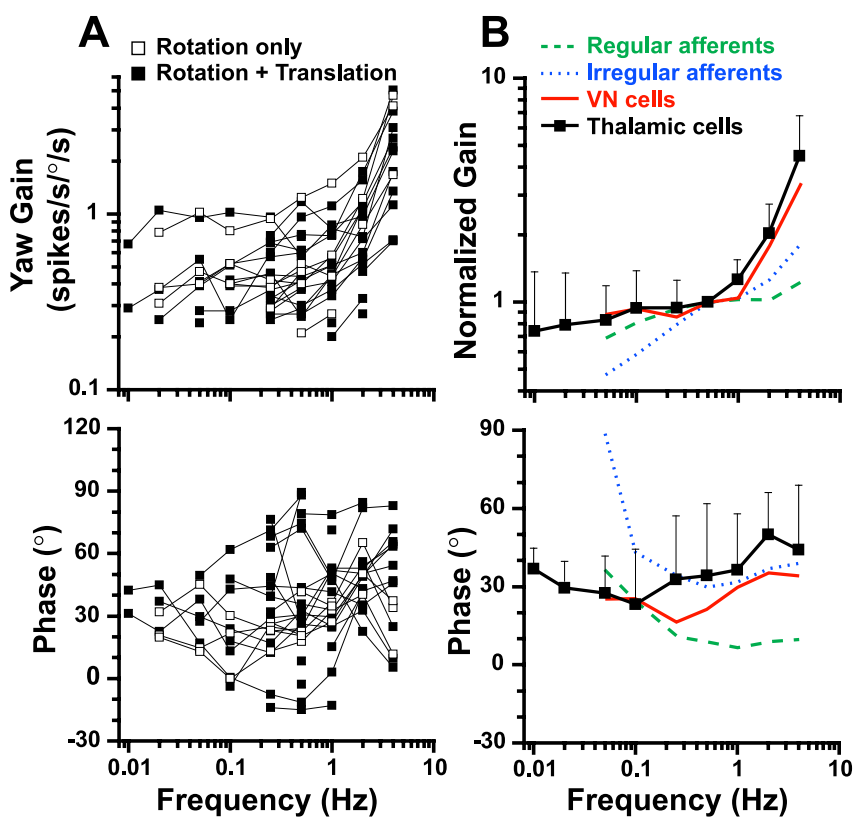

Figure 2. Response dynamics of thalamic neurons during yaw rotation. $\boldsymbol{A}$, Each line represents an individual cell's response gain and phase. Open symbols, Thalamic neurons responding to yaw rotation only. Filled symbols, Neurons with modulation during both yaw rotation and horizontal plane translation. A phase of $0^{\circ}$ illustrates responses in phase with head velocity. $\boldsymbol{B}$, Mean normalized gain and phase ( $\pm S D$ ) are compared with corresponding data from horizontal semicircular canal afferents (regular afferents, green dashed lines; irregular afferents, blue dotted lines) (replotted with permission from Haque et al., 2004) and VN neurons (red solid line; replotted with permission from Dickman and Angelaki, 2004).

ized gains used to compute the averages in Figure $2 B$ (top) reflected the responsiveness of each cell relative to its $0.5 \mathrm{~Hz}$ sensitivity (with the normalized gain at $0.5 \mathrm{~Hz}$ being 1). This normalization was necessary to preserve the frequencydependent changes in gain, given the different yaw motion gains of thalamic neurons.

Also superimposed in Figure $2 B$ are mean normalized response gain and phase obtained from primary semicircular canal afferents [green and blue lines; data from Haque et al. (2004)] and VN neurons [red lines; data from Dickman and Angelaki (2004); no such data are currently available for cerebellar cells]. The similarity between thalamic and VN response dynamics is notable. Both neuronal populations exhibited response gains that increased with frequency (Fig. $2 B$, top), and had persistent phase leads at all frequencies (Fig. $2 B$, bottom). As discussed previously for VN cells (Dickman and Angelaki 2004), these response dynamics differ from those of regularly and irregularly firing semicircular canal afferents (Fig. $2 \mathrm{~B}$, black and red solid lines vs green and blue dashed lines). Notably, all data were collected and processed using identical stimuli and analyses.

Perhaps the most noticeable aspect of yaw responsiveness is that phase does not increase with decreasing frequency as sharply in thalamic units as is the case for semicircular canal afferents (Fernandez and Goldberg, 1971). In fact, unlike canal afferents, there was no systematic dependence of response phase on frequency in thalamic neurons (ANCOVA, $F_{(5,41)}=2.2 ; p=0.08$, using six neurons tested at all frequencies between 0.02 and $4 \mathrm{~Hz}$ ). The absence of low-frequency phase leads, which are characteristic of primary semicircular canal afferents, suggest that rotational signals in the thalamus have been processed by the velocity storage integrator (Cohen et al., 1977; Raphan et al., 1979) (see Discussion). 
Response properties during horizontal plane translation

The modulation of 55 neurons was also characterized during both lateral and foreaft translation. There was a large cell-tocell variability in thalamic cell responses to translation, similar to that found in $\mathrm{VN}$ and $\mathrm{CN}$ neurons (Angelaki and Dickman, 2000; Dickman and Angelaki, 2002; Shaikh et al., 2005a). We have used a spatiotemporal analysis to describe each cell's tuning as a set of two orthogonal response vectors (Angelaki, 1991; Angelaki and Dickman, 2000). This analysis represents a generalization of cosine tuning that allows a nonzero minimum response gain and phase that can change as a function of motion direction (Angelaki, 1991; Bush et al., 1993; Angelaki and Dickman, 2000). In the present study, it was used to compute a maximum response gain and phase, as well as the corresponding preferred direction for each cell and each stimulus frequency. The departure from cosine tuning is captured by the "tuning ratio," defined in the range between 0 and 1 , as the ratio of the minimum over the maximum neural response gain.

Figure $3 A$ plots the distribution of tuning ratios during translation at $0.5 \mathrm{~Hz}$, which was broad, and similar to that found in VN/CN neurons (Angelaki and Dickman, 2000; Dickman and Angelaki, 2002; Shaikh et al., 2005a). Thalamic neurons with tuning ratios close to zero were mostly cosine-tuned during translation along different directions in the horizontal plane. Figure $3 B$ illustrates the corresponding distribution of maximum response directions and sensitivities at 0.5 $\mathrm{Hz}$. As in the VN and FN, maximum response directions of thalamic neurons were broadly and nearly uniformly distributed within the horizontal plane (uniformity test, $p=0.036$ ) (see Materials and Methods). At $0.5 \mathrm{~Hz}$, translational gains along the maximum response direction averaged $103.8 \pm 78.3$ (range, 29.8-355.2).

Figure $3 C$ summarizes how the gain and phase along the maximum response direction (expressed relative to linear acceleration) varied with frequency. Specifically, response gain decreased with frequency (ANCOVA, $F_{(54,137)}=12.9 ; p<0.001$ ), whereas there was a large scatter in the response phase from cell to cell. Figure $3 D$ shows the corresponding average gain (normalized to unity at $0.5 \mathrm{~Hz})$ and phase $( \pm \mathrm{SD})$. Also superimposed in Figure $3 D$ is the gain and phase dependence on frequency for neurons in the cerebellar nuclei (mostly rostral fastigial) (Shaikh et al., 2005a). Data from VN neurons are not shown because VN cell dynamics were more variable, ranging from gain increases to gain decreases, and phase lags to phase leads (Angelaki and Dickman, 2000; Dickman and Angelaki, 2002).

The gain dependence with respect to frequency was similar for thalamic and CN cells (Fig. 3C, top) (ANOVA with repeated measures, $\left.F_{(5,55)}=0.9 ; p=0.49\right)$. However, the dependence of response phase on frequency differed between thalamic and $\mathrm{CN}$ cells (Fig. 3D, bottom) (ANOVA with repeated measures, $F_{(5,55)}$ $=4.0 ; p=0.003)$, because $\mathrm{CN}$ phase increased with frequency, but thalamic cells showed little change in mean phase lag. Inspec- tion of Figure $3 C$ (bottom) shows that, like brainstem and cerebellar cells, thalamic neurons carry linear motion signals in a distributed manner, with response phases that vary greatly among neurons. Such a distributed representation of linear motion signals represents a hallmark of otolith-related neurons in the vestibular and deep cerebellar nuclei (Angelaki and Dickman, 2000; Dickman and Angelaki, 2002; Shaikh et al., 2005a).

\section{Response properties during earth-horizontal axis} (roll/pitch) rotations

Twenty-one cells responded during roll and/or pitch rotations from an upright orientation. These roll/pitch oscillations activated not only the semicircular canals, but also otolith afferents (as the head changed orientation relative to gravity). Thus, response modulation under these conditions could reflect signals arising from either one or both vestibular end organs. To ascertain whether thalamic neurons received signals from both otolith and semicircular canals, we tested their responses not only during roll/pitch rotation but also translation. Responses from two example cells tested during both lateral translation and roll rotation (referred to here as "tilt") have been illustrated in Figure 4, $A$ and $B$, respectively. One of the cells (1) modulated similarly during the translation and tilt stimuli (note that the amplitude of the two movements was adjusted such that the components of linear acceleration along the interaural axis were identical) (see Materials and Methods). Thus, this cell's response could be explained by selective activation of otolith afferents, which have been shown to encode net linear acceleration regardless of whether the stimulus arises from actual translation or tilt relative to gravity (Fernandez and Goldberg, 1976; Angelaki et al., 2004). In contrast, cell 2 responded very differently during the translation and tilt stimuli. Although it exhibited a clear modulation during translation, it 


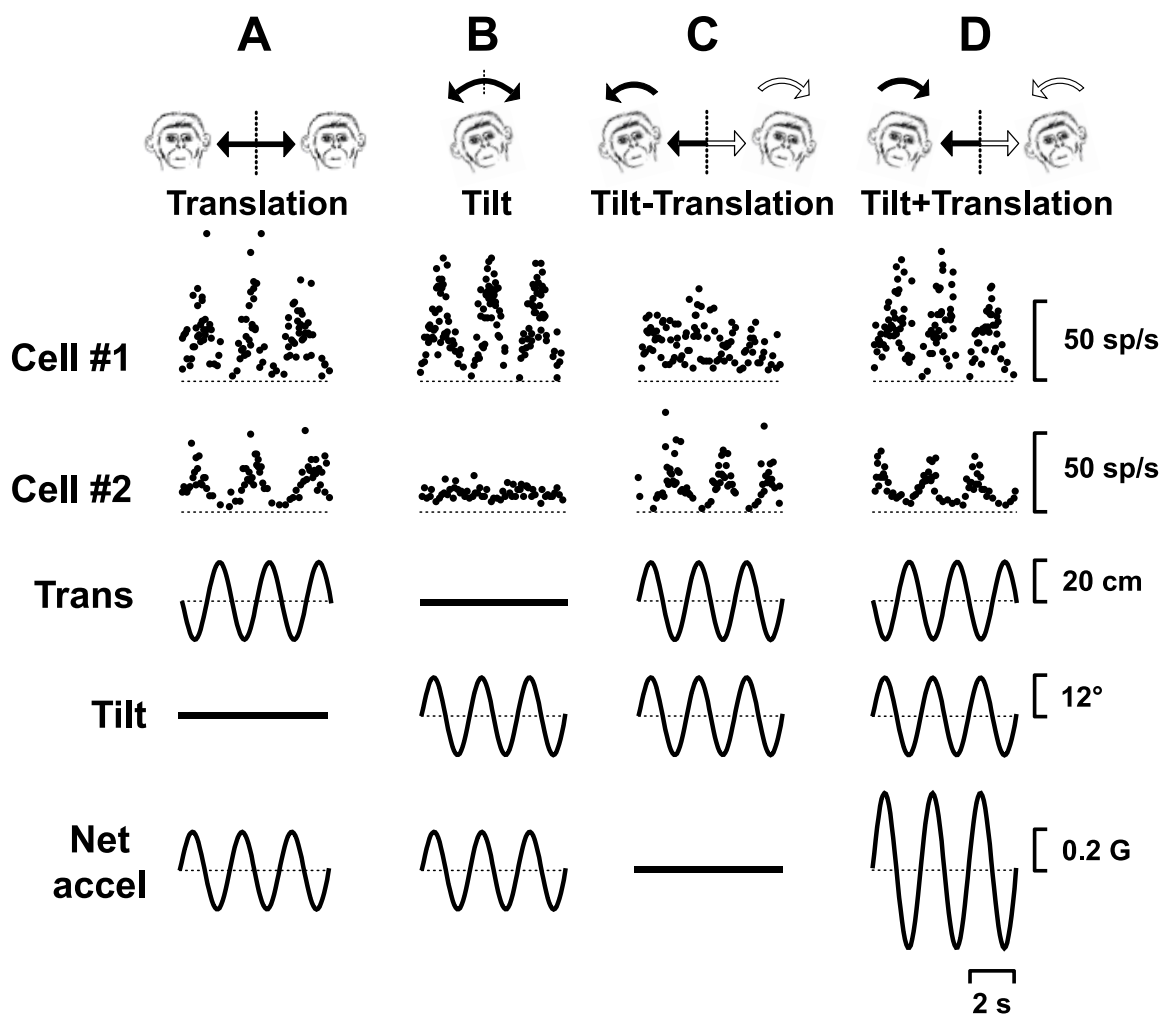

Figure 4. Examples from two thalamic neurons, one of which (cell 1) encodes net gravitoinertial acceleration, and the other (cell 2) selectively modulates during translation, while ignoring changes in the orientation of the head relative to gravity. $\boldsymbol{A}-\boldsymbol{D}$, Four stimulus protocols were used: translation only $(\boldsymbol{A})$, tilt only $(\boldsymbol{B})$, tilt minus translation $(\boldsymbol{C})$, and tilt plus translation protocols $(\boldsymbol{D}$; $0.5 \mathrm{~Hz}$ ). The stimulus traces (bottom 3 rows) show linear sled position (Trans), roll tilt position (Tilt) and net linear acceleration (Net accel). sp, Spikes. $G=9.8 \mathrm{~m} / \mathrm{s}^{2}$.

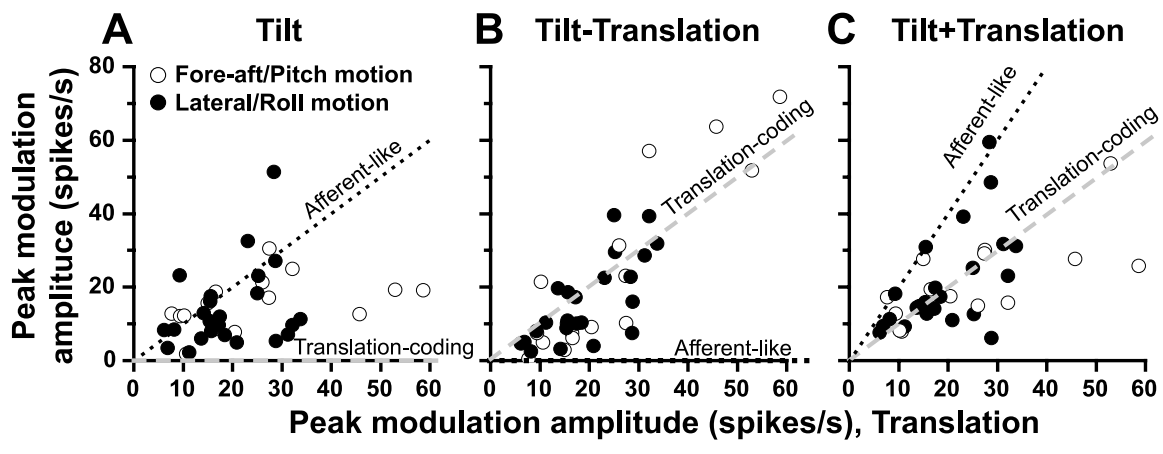

Figure 5. $\boldsymbol{A}-\boldsymbol{C}$, Summary of peak modulation amplitude during tilt $(\boldsymbol{A})$, tilt minus translation $(\boldsymbol{B})$, and tilt plus translation $(\boldsymbol{C})$ as a function of the respective responses during translation only motion. Each symbol corresponds to a cell, shown for the bestresponding translation direction (open symbols, fore-aft translation and pitch rotation; filled symbols, lateral translation and roll rotation). The predictions of an afferent-like and translation-coding models have been illustrated with the black, dotted, and gray dashed lines, respectively.

showed little modulation when the same interaural axis acceleration was the result of tilt (Fig. $4 A, B$ ). Obviously, the responses of this cell cannot be explained by activation of otolith afferents alone, suggesting that the cell's response also reflects a semicircular canal-driven signal.

Response properties during combinations of tilt and translation

To further explore the nature of vestibular information carried by thalamic neurons, we also used combinations of translation and tilt that could be placed either in or out of phase (see Materials and Methods). The responses of the two example cells during tilt minus translation and tilt plus translation are illustrated in Figure 4, $C$ and D. For the combined movements, the actual inertial acceleration was the same as that during translation only motion, yet the net gravitoinertial acceleration could either be nulled (tilt minus translation) or doubled (tilt plus translation) (Fig. 4, net accel traces). As shown previously (Fernandez and Goldberg, 1976; Angelaki and Dickman, 2000; Angelaki et al., 2004), primary otolith afferents encode the net gravitoinertial acceleration, modulating similarly during translation or tilt, and transmit no motion information during the tilt minus translation condition. This was also the case for some thalamic cells (e.g., cell 1). In contrast, other cells (e.g., cell 2) modulated similarly during translation, tilt minus translation and tilt plus translation, although they ignored changes in head orientation relative to gravity (tilt condition).

These two example cells illustrated in Figure 4 represent the two extremes among the thalamic neurons we encountered. As will be summarized next, most cells exhibited intermediate properties (i.e., they modulated during both the translation and tilt stimuli, albeit with different amplitudes), suggesting that they received convergence from both otolith and semicircular canal signals. How the thalamic cell population responded to tilt, translation, and their combinations has been illustrated in Figure 5, where peak modulation amplitude during the tilt, tilt minus translation, and tilt plus translation stimuli are compared with responses during translation. During tilt, translationselective neurons should not modulate and peak firing rates would be zero (Fig. $5 A$, gray dashed line falling along the abscissa). On the other extreme, afferent-like neurons should modulate similarly during tilt and translation, with peak firing rates falling along the unity-slope line (Fig. 5A, black, diagonal dotted lines). Many cells modulated similarly during tilt and translation, although others exhibited smaller modulation during tilt compared with translation. As a population, responses during tilt and translation were different (paired $t$ test, $p=0.0016)$, but correlated $\left(R^{2}=\right.$ $0.11 ; p=0.04)$ with a slope of $0.53([0.17,1.99], 95 \% \mathrm{CI})$.

For the combined movement trajectories (tilt minus translation and tilt plus translation), translation-selective neurons should respond in a manner similar to their activity during translation only motion, such that the data should fall along the unityslope line (Fig. $5 B, C$, gray, diagonal dashed lines). Indeed, many cells had peak firing rates that were similar to those during translation only motion, whereas others exhibited responses that were proportional to the net acceleration. At the population level, cell responses during the combined protocols were not different from 
those during translation only motion (paired $t$ test, tilt minus translation vs translation, $p=0.42$; tilt plus translation vs translation, $p=0.78$ ).

We used linear regression analyses and partial correlation coefficients to quantify whether each thalamic cell fell into one of two categories: "afferent-like" (i.e., firing rate $=\mathrm{k} \alpha$ ), which encode net acceleration, or "translation-coding" (i.e., firing rate $=k t=k(\alpha+g))$, where $t=\alpha+g$ is translational acceleration, $\alpha$ is net acceleration, and $g$ the gravitational acceleration (Angelaki et al., 2004; Shaikh et al., 2005b). This was done by simultaneously fitting the responses of each cell to all four stimuli (translation, tilt, tilt plus translation, and tilt minus translation) and comparing them with predicted values from the afferent-like and translation-coding models (see Materials and Methods). To simplify plotting and visual interpretation, the variances of these partial correlation coefficients were normalized using Fisher's $r$-to- $z$ transform (Angelaki et al., 2004; Smith et al., 2005). When the $z$-transformed partial correlation coefficients of the translation-coding model are plotted versus the respective afferent-like $z$-scores, the plot can be separated into regions in which data points can be distinguished as being better correlated with one model versus the other at a particular level of significance (Fig. 6A, dashed lines) $(p=0.01)$. Data falling in the upper left quadrant reflect translation-coding neurons, whereas data in the lower right correspond to afferent-like neurons.

Thalamic neuron responses were broadly distributed (Fig. 6A), with some cells better encoding translation (red squares in top left quadrant; $p<0.01$ ) and others net gravitoinertial acceleration (green pentagons in bottom right quad-

rant). Those cells that could not be distinguished into afferentlike or translation-coding at a level of significance of better than a $p$ value of 0.01 fell within the area between the parallel dashed lines (black triangles). For a subpopulation of cells tested at 0.16 and $1 \mathrm{~Hz}$, the $0.5 \mathrm{~Hz}$ classification persisted, with only a small dependence of the $z$-transformed correlation coefficients on frequency [multivariate ANOVA (MANOVA), $F_{(4,13)}=4.6 ; p=$ 0.02 ] (Fig. $6 B$ ). How thalamic neuron responses compare with those of VN and FN cells is illustrated in Figure 6C, where the $\mathrm{z}$-scores of thalamic neurons have been superimposed on those from the brainstem and cerebellum. As a population, thalamic neuron responses were not different from those in the VN (Fig. $6 C$ ) (MANOVA, $\left.F_{(2,106)}=0.20 ; p=0.82\right)$, but they differed from those in the CN (MANOVA, $F_{(2,106)}=15.0 ; p<0.001$ ). Overall, there were more translation-coding neurons in the $\mathrm{CN}$, compared with the VN and thalamus.

These conclusions were further corroborated when we considered a more general framework. Specifically, we also used a "distributed convergence" model (i.e., firing rate $=k_{1} \alpha+k_{2}$ g)
B $\begin{aligned} & \text { Afferent-like cells } \\ & \text { Translation-coding cells } \quad \text { C } \triangle \text { CN cells } \\ & \Delta \text { VN cells }\end{aligned}$ $\begin{array}{ll}\nabla \text { Translation-coding cells } & \diamond \text { VN cells } \\ \nabla \nabla \text { Unclassified cells } & \text { Thalamic cells }\end{array}$ Translation-coding

Translation-coding

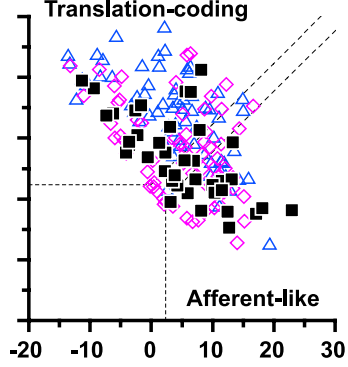

z-transformed correlation, afferent-like

Figure 6. Scatter plots of $z$-scores corresponding to the partial correlation coefficients for fits of each cell's responses with

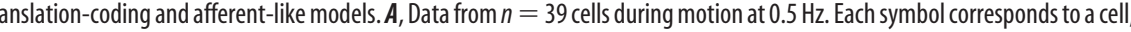
cells tested at more than one frequency (data connected with lines). C Thalamic cell data (solid squares) are compared with the recorded previously in CN neurons (blue triangles) and VN neurons (magenta diamonds). The superimposed dashed lines the cell's best-responding translation direction (open symbols, fore-aft translation and pitch rotation; filled symbols, lateral translation and roll rotation). VN/CN data replotted with permission from Angelaki et al. (2004).
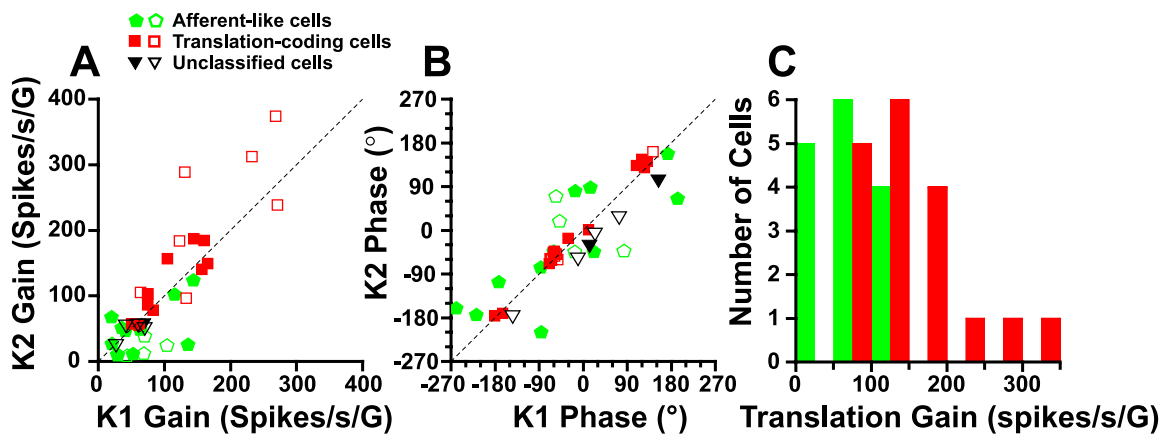

Figure 7. $\quad \boldsymbol{A}, \boldsymbol{B}$, Relationship between the $k_{1}$ and $k_{2}$ coefficients (decomposed into amplitude and phase) for each cell. Dotted being best fitted with the afferent-like or translation-coding model (from Fig. 6; green pentagons vs red squares, respectively (open symbols, fore-aft translation and pitch rotation; filled symbols, lateral translation and roll rotation). C, Distribution of translational response gains for afferent-like (green bars) and translation-coding (red bars) cells.

(Angelaki et al., 2004; Green et al., 2005), which has been shown previously to best account for the firing rate modulation of $\mathrm{VN}$ and CN neurons (Angelaki et al., 2004; Green et al., 2005). This model describes neural firing rates as a combination of net and gravitational acceleration, and it differs from the translationcoding model in that it allows for these components to combine with unequal weights (i.e., in general, coefficients $k_{1} \neq k_{2}$ ). Thus, this latter model provides an estimate of the extent to which each acceleration component, $\alpha$ (otolith-driven component) and $g$ (semicircular canal-driven component), contributes to an individual cell's activity. Figure 7, $A$ and $B$, plot the gain and phase of these coefficients as a function of each other. Like VN and CN neurons, the amplitudes of the two coefficients, $k_{1}$ and $k_{2}$, were not statistically different from each other (paired $t$ test, $p>0.05$ ), and were linearly correlated with slopes of 1.43 (gain, [1.1, 1.9]; 95\% CI) and 0.92 (phase, $[0.8,1.1]$; 95\% CI). For many afferentlike cells (green pentagons), $k_{1} \neq k_{2}$ (including both gain and phase). In contrast, the coefficients of translation-coding cells (red squares) were more $\operatorname{similar}\left(k_{1} \approx k_{2}\right.$, particularly in the case of 

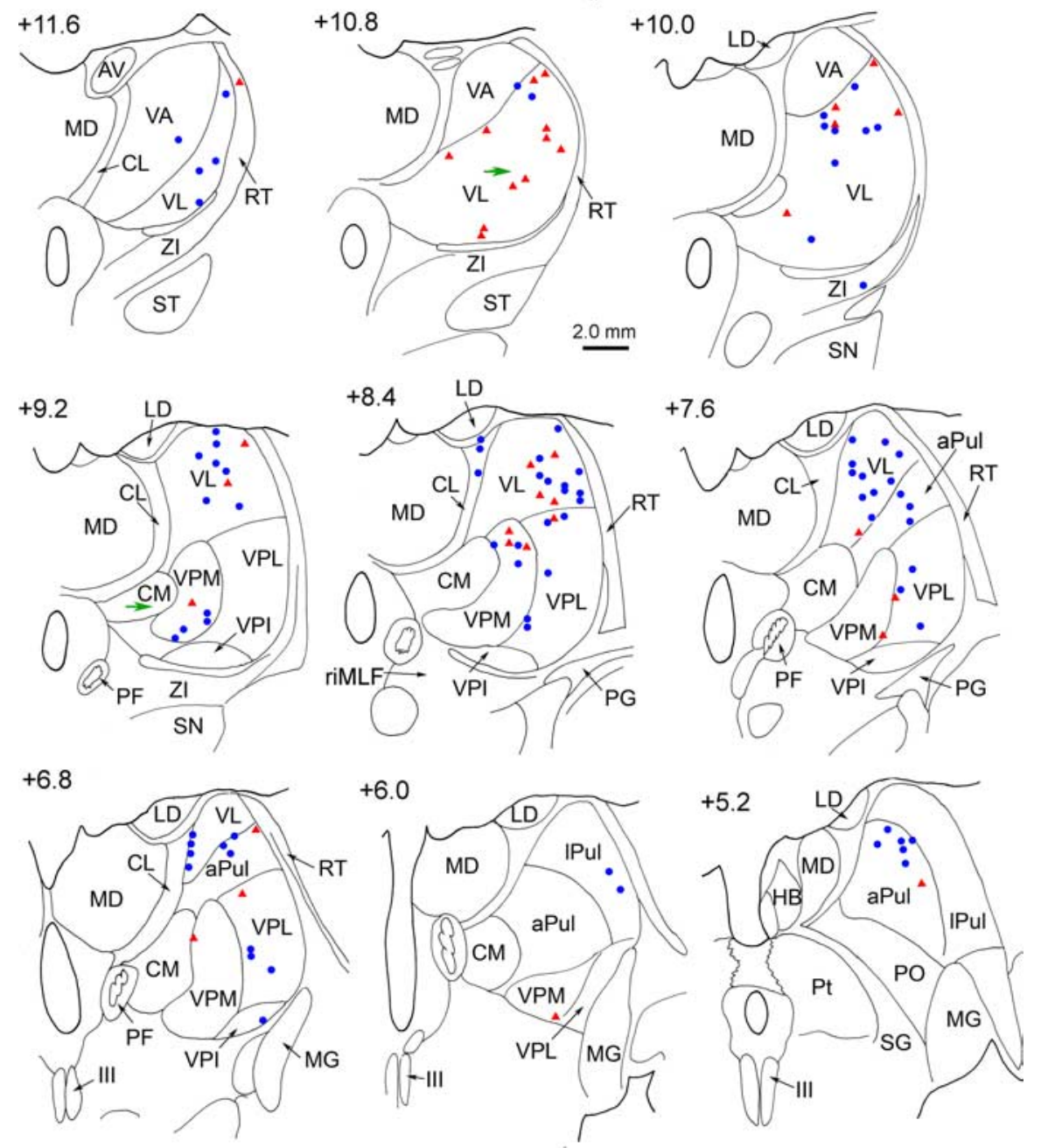

Figure 8. Reconstructed locations of motion-sensitive thalamic neurons in representative frontal brain sections. Cells recorded bilaterally have been superimposed in the right half of each section. Consecutive sections are arranged in rostral to caudal order. The numbers represent distance from the interaural line, and were computed by noting the location of marking lesions and the rostral end of the oculomotor nucleus with respect to AP levels shown in the atlas of Paxinos et al. (2000). Magenta triangles indicate neurons recorded from the animal with histology. Blue circles represent neurons from the second, surviving animal. Green arrows point to the electrolytic lesions (section +10.8 and +9.2 ). APul, Anterior pulvinar nucleus; $\mathrm{AV}$, anteroventral nucleus; $\mathrm{CL}$, centrolateral nucleus; CM, central medial nucleus; HB, habenula; III, oculomotor nucleus; LD, lateral dorsal nucleus; IPul, lateral pulvinar nucleus; $M D$, mediodorsal nucleus; $M G$, medial geniculate nucleus; $\mathrm{PF}$, parafascicular nucleus; $\mathrm{PG}$, perigeniculate nucleus; Pt, pretectum; P0, posterior nucleus; RT, reticular thalamic nucleus; SG, suprageniculate; SN, substantia nigra; ST, subthalamic nucleus; VA, ventral anterior nucleus.

phase) (Fig. 7B). Notably, translation-coding neurons had gains that were significantly larger than those of afferent-like, net accelerationcoding cells ( $t$ test, $p=0.047$ ) (Fig. 7C). In our sample of thalamic cells, we did not observe tilt-like neurons similar to those described by Zhou et al. (2006) in the vestibular nuclei.

\section{Distribution of thalamic vestibular neurons}

Examination of the locations from which we had recorded vestibularly responsive units revealed that these cells were present over a large thalamic region. Specifically, they covered an area extending nearly $7 \mathrm{~mm}$ in the anteroposterior dimension and 7 $\mathrm{mm}$ in the dorsoventral dimension. We examined tissue between 4 and $10 \mathrm{~mm}$ from the midline, and found vestibularly responsive units scattered throughout this region. It should be noted that we observed no clear relationship between the properties we analyzed for the vestibular responsive neurons (e.g., whether they were more afferent like, or more involved in translation coding) and the location of neurons in the thalamus. We reconstructed the recorded units in one of the animals using electrolytic lesions to establish points of reference (see Materials and Methods). Figure 8 shows the reconstruction of the vestibular units from this animal (red triangles) and a superimposed second (surviving) animal (blue circles). The majority of vestibular units were found within the VL, with responsive cells distributed from its rostral $(+11.6 \mathrm{~cm})$ to caudal $(+6.8)$ end. The main population of these units appeared to make up a rostrocaudally running column within the VL. At more caudal levels (+9.2-6.8), a significant number of vestibular units were present in VPL and VPM. The area of VL and VPL between +9.2 and 7.6 appears to be the core region in which vestibular units have been described previously as lying in VPLo (Deecke et al., 1977), although we observed units dorsal to theirs as well. In addition, it should be noted that the region designated as VPI by Deecke et al. (1974) would fall within our designation of VPM (section +9.2). The most caudal recorded vestibular cells were found within the anterior and lateral pulvinar (+7.6-5.2). A few vestibular units were also located in the central lateral nucleus (CL) $(+8.4)$, VPI $(+6.8)$, and zona incerta (ZI) $(+10.0)$. This clearly represents a much broader area than that targeted by ascending vestibular nucleus axons, as previously described for the monkey (Lang et al., 1979). It is possible that neurons sensitive to vestibular stimulation might also be found medial to the CL, as these areas were not explored in the current study.

\section{Vestibulocerebellothalamic projections}

The area within which we found vestibular responsiveness was larger and extended further anteriorly and dorsally than the region in VP previously described as receiving direct projections from the vestibular nuclear complex. Consequently, we hypothesized that either primate vestibular nuclei inputs are actually more broadly distributed, like those of rodents (Nagata, 1986; Shiroyama et al., 1999), or that the thalamus might receive vestibular information from areas other than the VN. Because vestibular signals in VPL presumably originate from its $\mathrm{VN}$ input (Lang et al., 1979), we aimed an injection at a region dorsal to VPL to retrogradely label its inputs. The neuronal tracer WGA-HRP was injected into this vestibularly responsive site, as shown in Figure 9. The injection site was centered within dorsolateral VL, and extended into the adjacent reticular thalamic nucleus and internal capsule. The ventral edge of the injection site impinged on the dorsal VPL border. Strikingly, no labeled neurons were found in the vestibular nuclei, and with the exception of the locus ceruleus and a few cells in the gracile nucleus, the brainstem was nearly free of label. Instead, nearly all of the labeled cells were found in the CN.

Examples of the cerebellothalamic labeling seen after this injection are shown in Figure 10. The region of intense retograde 
label (Fig. 10A) is shown in higher magnification photomicrographs taken with crossed polarizers to demonstrate labeled multipolar neurons in the fastigial nucleus (Fig. 10 B), dentate nucleus (Fig. 10C), and anterior interposed nuclei (Fig. 10D). The distribution pattern of label in the $\mathrm{CN}$ is detailed in Figure 11. The vast majority of labeled neurons were found within the contralateral anterior interposed nucleus (Fig. $11 B-F)$. Labeled neurons extended from this region into the adjacent wing of the dentate nucleus (Fig. 11A-C). Medially, labeled cells were also present in portions of the contralateral rostral fastigial nucleus (Fig. $11 C$ $E$ ), and a few cells were found in the ipsilateral fastigial nucleus (Fig. 11C).

We confirmed the retrograde findings by examining the pattern of anterograde terminal labeling after injections of WGAHRP into the vestibular, fastigial and anterior interposed nuclei. To ease comparison, the observed pattern of terminal label was collapsed onto representative rostral and caudal sections in Figure 12. Injections of the fastigial nucleus (Fig. $12 \mathrm{~A} 1$ ) produced dense regions of terminal label in the contralateral VL (Fig. $12 A 2, A 3)$. In addition, terminal puffs were present laterally in VPL (Fig. 12A3), and in CL and ZI (Fig. 12A2,A3). Injections of the anterior interposed nucleus (Fig. 12 B1) also produced dense terminal label within VL (Fig. 12 B2,B3). Terminal puffs were also present in lateral VPL, and in the paralemellar portion of the mediodorsal nucleus (MD) (Fig. 12 B3). By comparison, an injection of the vestibular nuclei (Fig. 12C1) produced a much smaller, lighter terminal field that was primarily located on either side of the border between VPL and VL (Fig. 12C2,C3). Small puffs of terminals were also present in VPM (Fig. 12C3) and CL (Fig. 12C2), as well as ZI (Fig. 12C2). For comparison, we have plotted the location of the neurons responsive to vestibular stimuli onto the same two levels (Fig. 12 D1,D2). The VN projections can only explain the presence of vestibular units on either side of the VPL/VL border. Vestibular signals must access the thalamus by some other route to produce the wider pattern of activity observed. In the case of VL, the pattern of terminals from the anterior interposed and fastigial nucleus can account for many (but not all) of these vestibular units. In fact, the distribution of vestibular responsive neurons extends dorsal to the plotted terminal fields into areas presumably supplied by other parts of the CN (Stanton, 1980; Thach, 1987). Comparison of these terminal fields also suggests the possibility that both vestibulothalamic and cerebelothalamic projections may converge in some places along the VPL/VL border, and in CL.

\section{Discussion}

These results suggest that a variety of different thalamic nuclei participate in the neuronal processing of vestibular information that is destined for cortex. They further suggest that a portion of the vestibular signals in the thalamus originate from the cerebel- lum, and not directly from the vestibular nuclei. Cerebellothalamic pathways for vestibular signal transmission to the cortex have not been specifically described. Nevertheless, neurons in the fastigial and anterior interposed nuclei exhibit strong vestibular modulation (Gardner and Fuchs, 1975; Büttner et al., 1991; Siebold et al., 1997, 1999; Zhou et al., 2001; Angelaki et al., 2004; Shaikh et al., 2004, 2005a,b). Furthermore, thalamic projections from these nuclei primarily terminate in VL (Fig. 12) (Stanton, 1980; Asanuma et al., 1983; Thach, 1987; Sakai et al., 1996; Middleton and Strick, 1997). Finally, retrograde labeling of CN neurons after an injection into a vestibular responsive region of dorsal VL supports this alternative pathway (Figs. 9-11).

\section{Vestibular thalamus: previous studies}

Electrical stimulation of the vestibular nerve has been shown to evoke large field potentials at disynaptic latencies (2-3 ms) in the ventral tier thalamic nuclei, (Deecke et al., 1974; Liedgren et al., 1976). In cats, electrical stimulation of the vestibular nerve suggests that short-latency otolith (mainly utricular) projections are primarily ipsilateral, whereas the semicircular canal pathway is mainly contralateral (Matsuo et al., 1994; Meng et al., 2001). Most of these electrically activated cells fell within the core region where we observed units: on either side of the VPL/VL border. 

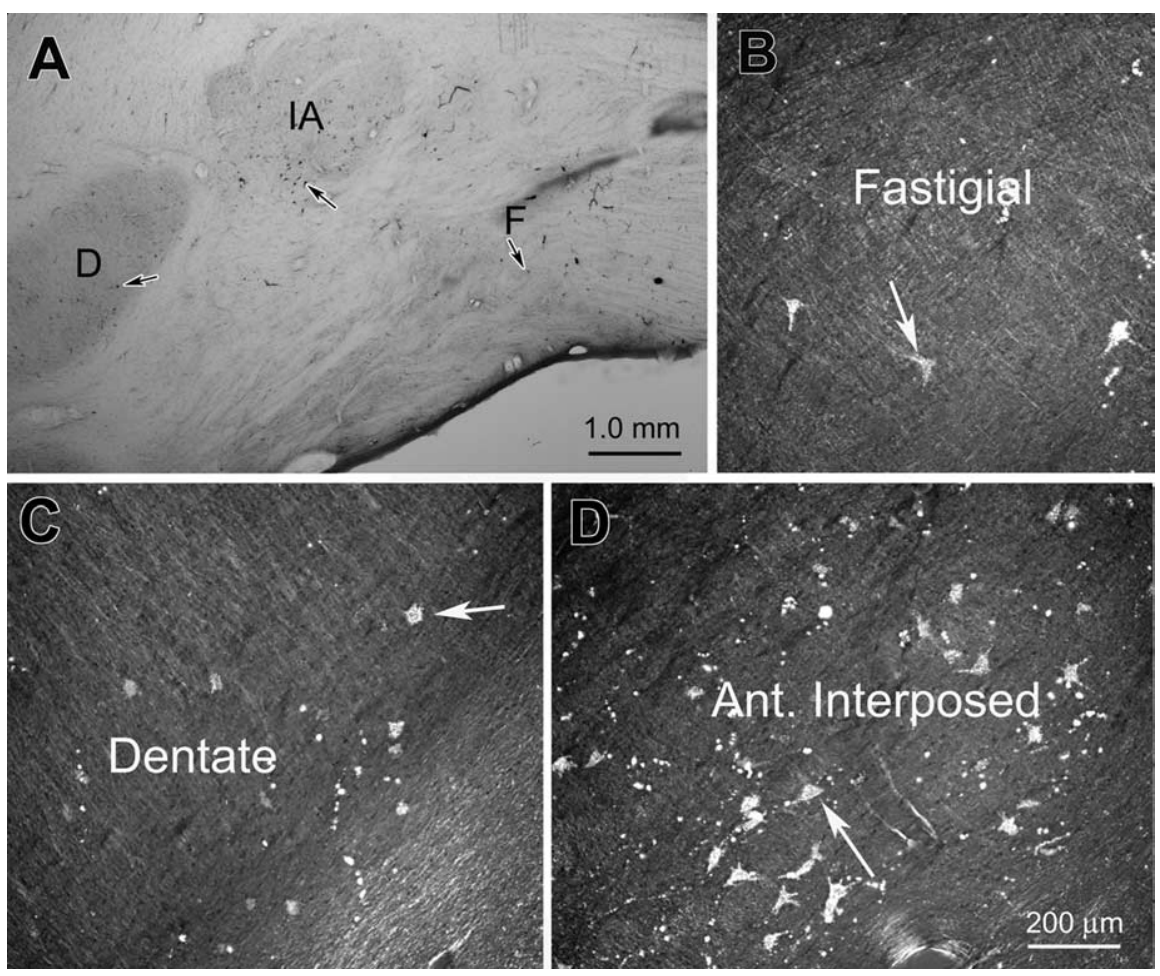

Figure 10. Examples of retrograde cell labeling in the cerebellar nuclei after the injection are shown in Figure 9. A, A lowmagnification view of a section through the nuclei. $\boldsymbol{B}-\boldsymbol{D}$, Higher magnification views from this same section taken with crossed polarizers to show labeled neurons in the fastigial, dentate, and anterior interposed nuclei, respectively. Arrows point to examples of labeled neurons. D, Dentate nucleus; $F$, fastigial nucleus; IA, anterior interposed nucleus.
A
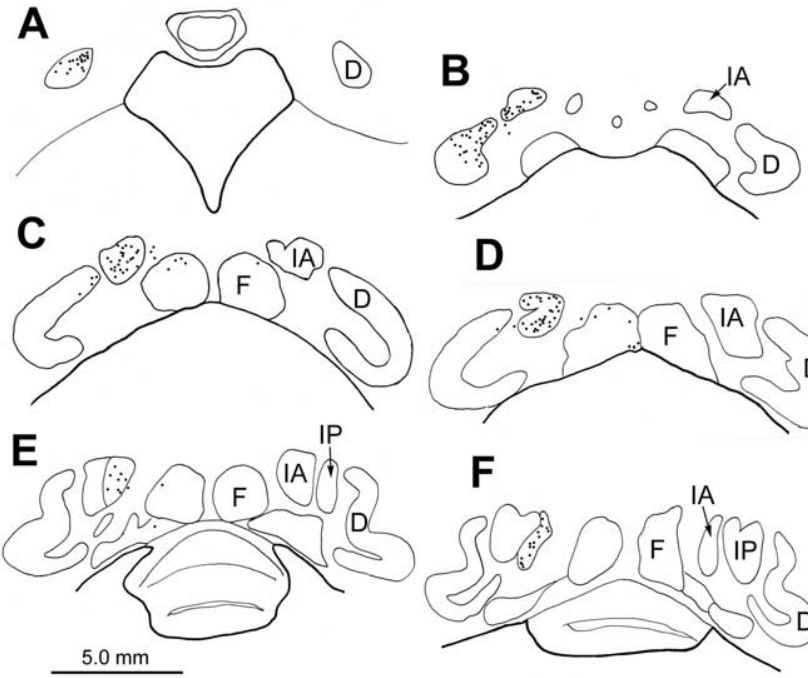

D

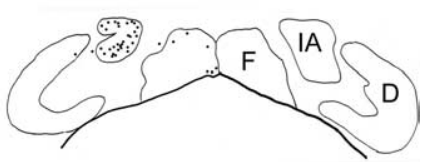

$\mathbf{F}$

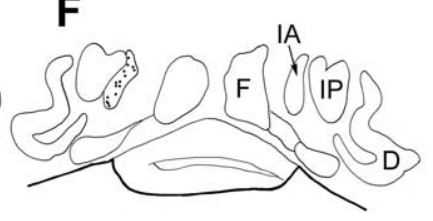

Figure 11. $A-F$, Distribution pattern of retrograde cell labeling within the cerebellar nuclei from the case illustrated in Figures 9 and 10. Most retrogradely labeled cells (dots) were located in the contralateral dentate and the anterior interposed nuclei. A few cells were found in the fastigial nuclei. D, Dentate nucleus; F, fastigial nucleus; IA, anterior interposed nucleus; IP, posterior interposed nucleus.

Anatomical evidence has also suggested that the vestibular nuclei projection in monkeys lies on either side of the border between the somatosensory VPL and somatomotor VL (Lang et al., 1979; Asanuma et al., 1983) (Fig. 12C). Previous studies termed this region VPLo. However, we believe that a portion of this projection lies in the $\mathrm{VL}$, rostral and dorsal to the borders of VPL (Fig. 12C) (see Materials and Methods). This places it within the terminal territory of the $\mathrm{CN}$ (Fig. $12 A, B)$, suggesting that vestibular information from both $\mathrm{VN}$ and $\mathrm{CN}$ may converge on these neurons. In fact, the physiological and anatomical data presented here support the view that vestibular signals are spread even more widely within VL (compared with VPL), in line with the thalamic terminal zones of the CN (Fig. 12) (Batton et al., 1977; Stanton, 1980; Kalil, 1981; Asanuma et al., 1983). Notably, their presence in VL suggests that vestibular information is also sent to cortex anterior to the central fissure. Finally, our recordings suggest that other areas of thalamus, not supplied directly by the $\mathrm{VN}$ or $\mathrm{CN}$ (e.g., pulvinar) (Fig. 8), also take part in providing the cortex with vestibular information. The source of these signals remains to be determined.

\section{Responses during rotation}

To date, the vestibular responses of primate thalamic neurons have only been tested during yaw rotation (Büttner and Henn, 1976; Büttner et al., 1977; Magnin and Fuchs, 1977). Similar to our results, few neurons exhibited eye movement sensitivity, and yaw responses were characterized by phase leads of $\sim 30^{\circ}$ (Büttner et al., 1977). The dynamics of thalamic neurons are similar to those previously reported in eye movementinsensitive VN neurons (Fig. 2 B) (Waespe and Henn, 1977; Dickman and Angelaki, 2004). Notably, like VN neurons, but unlike canal afferents, thalamic neurons showed little increase in phase lead, and only a relatively small drop in gain during low frequency rotations (Fig. 2) (Fernandez and Goldberg, 1971; Dickman and Angelaki, 2004). Thus, the rotational dynamics of thalamic neurons reflect the influence of velocity storage, a low-pass filter that improves the low frequency coding of angular velocity in the vestibulo-ocular reflex (Cohen et al., 1977; Raphan et al., 1979), and in rotational motion perception (Mergner et al., 1991; Howard et al., 1998; Okada et al., 1999).

\section{Responses during translation}

We investigated three properties of translational responses. First, the preferred response directions of thalamic neurons, like $\mathrm{VN}$ and $\mathrm{CN}$ cells, were distributed throughout the horizontal plane. Second, response phase varied greatly among cells, although response gain (re linear acceleration) typically had a consistent dependence on frequency. Thalamic translational response dynamics differed somewhat from those in VN and CN (Angelaki and Dickman, 2000; Dickman and Angelaki, 2002; Shaikh et al., 2005a), suggesting some form of additional processing. Finally, combinations of tilt (rotation) and translation stimuli were used to determine whether thalamic neurons selectively encode translation, or net linear acceleration. Like $\mathrm{VN}$ and $\mathrm{CN}$ cells, thalamic neurons represent a continuum. Although cells at the extremes exclusively encoded either translation or net linear acceleration, most showed intermediate properties. Notably, translation-coding signals exhibited greater sensitivity than net acceleration-coding signals.

We speculated previously that this distributed representation provided an efficient population code for transmitting both signals 

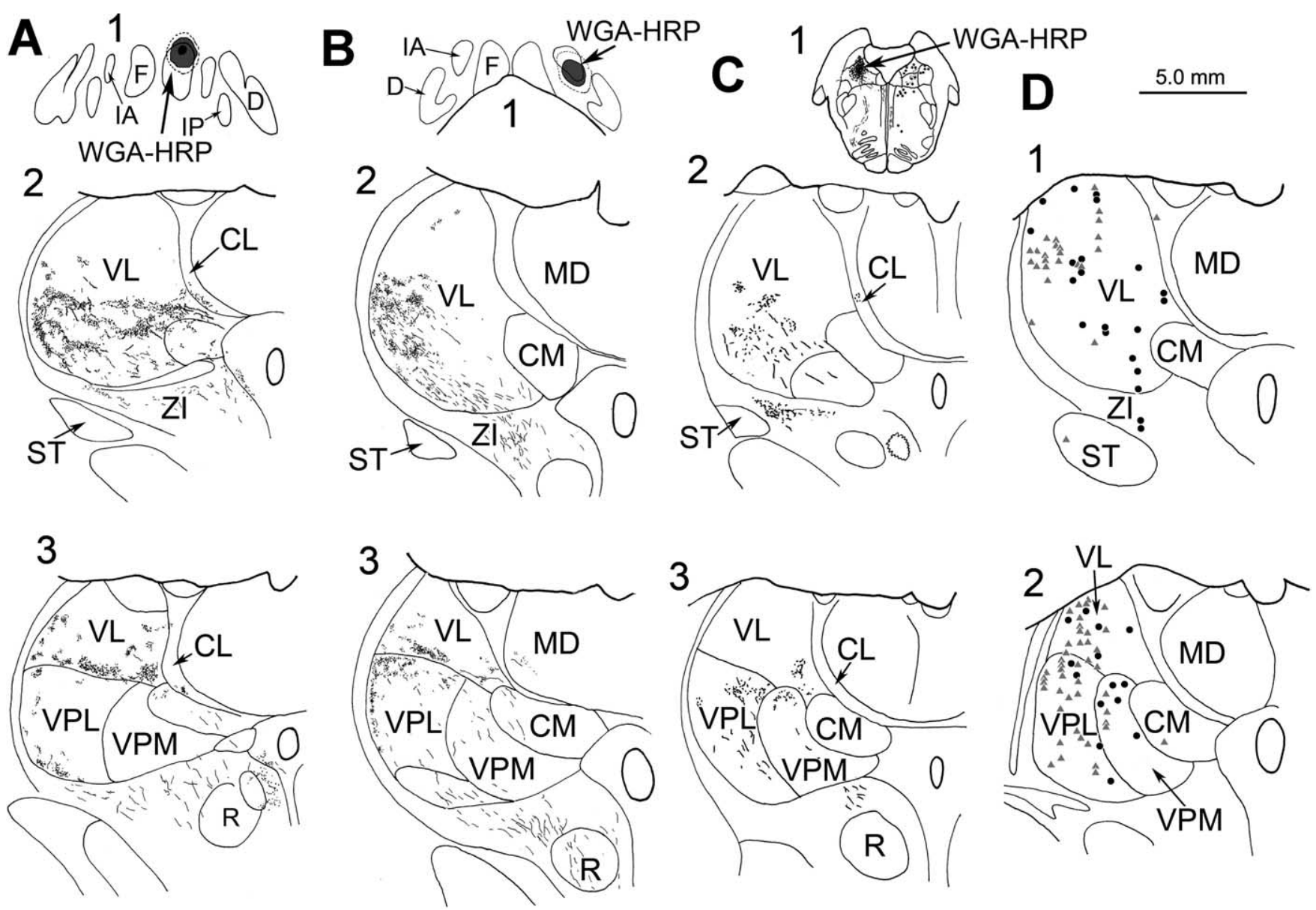

Figure 12. $\quad \boldsymbol{A}-\boldsymbol{D}$, Illustrations of terminal field patterns in the thalamus after injections of the $\mathrm{CN}(\boldsymbol{A}, \boldsymbol{B})$ and $\mathrm{VN}(\boldsymbol{C})$ in relation to the pattern of vestibular responsive neurons in the thalamus $(\boldsymbol{D})$. Black regions indicate injection sites in the fastigial nucleus ( $\boldsymbol{A} \mathbf{1}$, horizontal section), anterior interposed nucleus ( $\boldsymbol{B}$, frontal section), and vestibular nuclei ( $\boldsymbol{C}$, frontal section). Stipple indicates the pattern of terminals (A2-C3). The data from several sections have been collapsed onto two representative frontal sections through the rostral $(\boldsymbol{A 2}, \mathbf{B 2}, \mathbf{C}, \mathbf{D 1})$ and caudal $(\boldsymbol{A 3}, \mathbf{B 3}, \mathbf{C}, \mathbf{D 2})$ thalamus. In $\boldsymbol{D}$, circles indicate units from the injected animal and triangles indicate units from the surviving animal, plotted on the left for convenience of comparison. $C M$, central medial nucleus; $D$, dentate nucleus; F, fastigial nucleus; IA, anterior interposed nucleus; IP, posterior interposed nucleus; MD, mediodorsal nucleus; R, red nucleus; ST, subthalamic nucleus.

(Angelaki et al., 2004). In particular, we showed that $\mathrm{VN}$ and $\mathrm{CN}$ neurons carried two components of linear acceleration in different proportions: (1) an estimate of net linear acceleration originating from otolith afferent signals, and (2) an estimate of gravitational acceleration derived from a tilt-related signal originating from spatially and temporally transformed canal afferent signals (Angelaki et al., 2004; Yakusheva et al., 2007). Thus, a simple weighted average population code would extract either net linear acceleration (by assigning weights such that the second term is canceled) or translation (by assigning weights that give a population sum that is equal for the two components) (Angelaki et al., 2004).

We have shown here that thalamic neurons behave similarly (Fig. 7). The following question then arises: if these computations are really relevant, why do we not get unambiguous signals in the thalamus? The answer may lie in the diverse functions of vestibular signals. Clearly, although perception would greatly benefit from distinguishing translation from head orientation relative to gravity, the opposite is true for postural responses. Thus, we postulate that the distributed coding of translation and net acceleration in the thalamus reflects the functional need to have both signals available to serve various cortical functions.

\section{Vestibular cortex}

The diversity of vestibular neurons in the thalamus must be viewed in the context of the numerous vestibularly related corti- cal areas identified by responses to vestibular stimuli or electrical activation of the vestibular nerve. Some cortical vestibular signals may originate through corticocortical connections (Guldin et al., 1992; Stanton et al., 1995; Lewis and Van Essen, 2000), but ultimately these signals must reach cortex via the thalamus. Among these vestibular cortical regions are portions of the retroinsular cortex [parieto-insular vestibular cortex (PIVC)] (Grüsser et al., 1990a,b), and the neck regions of area 3a of primary somatosensory cortex $(3 \mathrm{aV})$ (Fredrickson et al., 1966; Schwarz and Fredrickson, 1971a,b; Odkvist et al., 1974; Büttner and Buettner, 1978; Guldin et al., 1992). In squirrel monkeys, $3 \mathrm{aV}$ receives projections from rostral and dorsal VPL (designated VPLo and VPLs by Akbarian et al., 1992), whereas PIVC receives its main thalamic input from caudal VPL and from the pulvinar (Akbarian et al., 1992). We observed vestibular responsive units in all these regions.

Other portions of parietal and temporal cortex showing vestibular activity include the anterior tip of the intraparietal sulcus (area 2v) (Büttner and Buettner 1978; Fredrickson et al., 1966; Schwarz and Fredrickson 1971a,b), the medial superior temporal area (Page and Duffy, 2003; Gu et al., 2006, 2007), and the ventral intraparietal area (Bremmer et al., 2002; Klam and Graf, 2003; Chen et al., 2007). Whether the pulvinar units we recorded could supply these parietal and temporal areas is presently unknown. Finally, vestibular responses have also been reported in the fron- 
tal eye fields (FEFs) (Fukushima et al., 2000; Ebata et al., 2004) and premotor/motor cortex (Fredrickson et al., 1966; BoisacqSchepens and Hanus, 1972; Guldin et al., 1992). The numerous vestibular units in VL, which are supplied by both the VN and $\mathrm{CN}$, are well positioned to transfer vestibular signals to premotor/ motor cortex. Vestibular signals in FEFs could originate from thalamic neurons in CL (Huerta et al., 1986), as terminals were observed there after both CN and VN injections (Fig. 12). Clearly, greater knowledge regarding the details of thalamocortical transmission of vestibular signals is needed to understand how the thalamus processes vestibular information and directs it to the cortical regions needing these signals. In particular, we need to determine what other signals, if any, are present on vestibular responsive neurons in VL, VPL, and the anterior pulvinar.

\section{References}

Akbarian S, Grüsser OJ, Guldin WO (1992) Thalamic connections of the vestibular cortical fields in the squirrel monkey (Saimiri sciureus). J Comp Neurol 326:423-441.

Angelaki DE (1991) Dynamic polarization vector of spatially tuned neurons. IEEE Trans Biomed Eng 38:1053-1060.

Angelaki DE, Dickman JD (2000) Spatiotemporal processing of linear acceleration: primary afferent and central vestibular neuron responses. J Neurophysiol 84:2113-2132.

Angelaki DE, McHenry MQ, Newlands SD, Dickman JD (1999) Functional organization of primate translational vestibulo-ocular reflexes and effects of unilateral labyrinthectomy. Ann NY Acad Sci 871:136-147.

Angelaki DE, McHenry MQ, Hess BJ (2000) Primate translational vestibuloocular reflexes. I. High-frequency dynamics and three-dimensional properties during lateral motion. J Neurophysiol 83:1637-1647.

Angelaki DE, Green AM, Dickman JD (2001) Differential sensorimotor processing of vestibulo-ocular signals during rotation and translation. J Neurosci 21:3968-3985.

Angelaki DE, Shaikh AG, Green AM, Dickman JD (2004) Neurons compute internal models of the physical laws of motion. Nature 430:560-564.

Asanuma C, Thach WT, Jones EG (1983) Distribution of cerebellar terminations and their relation to other afferent terminations in the ventral lateral thalamic region of the monkey. Brain Res 286:237-265.

Batton III RB, Jayaraman A, Ruggerio D, Carpenter MB (1977) Fastigial efferent projections in the monkey: an autoradiographic study. J Comp Neurol 174:281-306.

Boisacq-Schepens N, Hanus M (1972) Motor cortex vestibular responses in the chloralosed cat. Exp Brain Res 14:539-549.

Bremmer F, Klam F, Duhamel JR, Ben Hamed S, Graf W (2002) Visualvestibular interactive responses in the macaque ventral intraparietal area (VIP). Eur J Neurosci 16:1569-1586.

Bush GA, Perachio AA, Angelaki DE (1993) Encoding of head acceleration in vestibular neurons. I. Spatiotemporal response properties to linear acceleration. J Neurophysiol 69:2039-2055.

Büttner U, Buettner UW (1978) Parietal cortex (2v) neuronal activity in the alert monkey during natural vestibular and optokinetic stimulation. Brain Res 153:392-397.

Büttner U, Henn V (1976) Thalamic unit activity in the alert monkey during natural vestibular stimulation. Brain Res 103:127-132.

Büttner U, Lang W (1979) The vestibulocortical pathway: neurophysiological and anatomical studies in the monkey. Prog Brain Res 50:581-588.

Büttner U, Henn V, Oswald HP (1977) Vestibular-related neuronal activity in the thalamus of the alert monkey during sinusoidal rotation in the dark. Exp Brain Res 30:435-444.

Büttner U, Fuchs AF, Markert-Schwab G, Buckmaster P (1991) Fastigial nucleus activity in the alert monkey during slow eye and head movements. J Neurophysiol 65:1360-1371.

Chen A, DeAngelis GC, Angelaki DE (2006) Responses to threedimensional rotation and translation in the parieto-insular vestibular cortex (PIVC) of rhesus monkey. Soc Neurosci Abstr 32:244.6.

Chen A, Henry E, DeAngelis GC, Angelaki DE (2007) Comparison of response to three-dimensional rotation and translation in the ventral intraparietal (VIP) and medial superior temporal (MST) areas of rhesus monkey. Soc Neurosci Abstr 33:715.19.

Chen-Huang C, Peterson BW (2006) Three dimensional spatial-temporal convergence of otolith related signals in vestibular only neurons in squirrel monkeys. Exp Brain Res 168:410-426.

Cohen B, Matsuo V, Raphan T (1977) Quantitative analysis of the velocity characteristics of optokinetic nystagmus and optokinetic afternystagmus. J Physiol (Lond) 270:321-344.

Deecke L, Schwarz DW, Fredrickson JM (1974) Nucleus ventroposterior inferior (VPI) as the ventibular thalamic relay in the rhesus monkey. I. Field potential investigation. Exp Brain Res 20:88-100.

Deecke L, Schwarz DW, Fredrickson JM (1977) Vestibular responses in the rhesus monkey ventroposterior thalamus. II. Vestibulo-proprioceptive convergence at thalamic neurons. Exp Brain Res 30:219-232.

Dickman JD, Angelaki DE (2002) Vestibular convergence patterns in vestibular nuclei neurons of alert primates. J Neurophysiol 88:3518-3533.

Dickman JD, Angelaki DE (2004) Dynamics of vestibular neurons during rotational motion in alert rhesus monkeys. Exp Brain Res 155:91-101.

Ebata S, Sugiuchi Y, Izawa Y, Shinomiya K, Shinoda Y (2004) Vestibular projection to the periarcuate cortex in the monkey. Neurosci Res 49:55-68

Fernandez C, Goldberg JM (1971) Physiology of peripheral neurons innervating semicircular canals of the squirrel monkey. II. Response to sinusoidal stimulation and dynamics of peripheral vestibular system. J Neurophysiol 34:661-675.

Fernandez C, Goldberg JM (1976) Physiology of peripheral neurons innervating otolith organs of the squirrel monkey. I. Response to static tilts and to long-duration centrifugal force. J Neurophysiol 39:970-984.

Fredrickson JM, Scheid P, Figge U, Kornhuber HH (1966) Vestibular nerve projection to the cerebral cortex of the rhesus monkey. Exp Brain Res 2:318-327.

Fukushima K, Sato T, Fukushima J, Shinmei Y, Kaneko CR (2000) Activity of smooth pursuit-related neurons in the monkey periarcuate cortex during pursuit and passive whole-body rotation. J Neurophysiol 83:563-587.

Fukushima J, Akao T, Takeichi N, Kurkin S, Kaneko CR, Fukushima K (2004) Pursuit-related neurons in the supplementary eye fields: discharge during pursuit and passive whole body rotation. J Neurophysiol 91:2809-2825.

Gardner EP, Fuchs AF (1975) Single-unit responses to natural vestibular stimuli and eye movements in deep cerebellar nuclei of the alert rhesus monkey. J Neurophysiol 38:627-649.

Green AM, Shaikh AG, Angelaki DE (2005) Sensory vestibular contributions to constructing internal models of self-motion. J Neural Eng 2:S164-S179.

Grüsser OJ, Pause M, Schreiter U (1990a) Localization and responses of neurones in the parieto-insular vestibular cortex of awake monkeys ( $\mathrm{Ma}$ caca fascicularis). J Physiol (Lond) 430:537-557.

Grüsser OJ, Pause M, Schreiter U (1990b) Vestibular neurones in the parieto-insular cortex of monkeys (Macaca fascicularis): visual and neck receptor responses. J Physiol (Lond) 430:559-583.

Gu Y, Watkins PV, Angelaki DE, DeAngelis GC (2006) Visual and nonvisual contributions to three-dimensional heading selectivity in the medial superior temporal area. J Neurosci 26:73-85.

Gu Y, Deangelis GC, Angelaki DE (2007) A functional link between area MSTd and heading perception based on vestibular signals. Nat Neurosci 10:1038-1047.

Guldin WO, Akbarian S, Grüsser OJ (1992) Cortico-cortical connections and cytoarchitectonics of the primate vestibular cortex: a study in squirrel monkeys (Saimiri sciureus). J Comp Neurol 326:375-401.

Haque A, Angelaki DE, Dickman JD (2004) Spatial tuning and dynamics of vestibular semicircular canal afferents in rhesus monkeys. Exp Brain Res 155:81-90.

Howard IP, Zacher JE, Allison RS (1998) Post-rotatory nystagmus and turning sensations after active and passive turning. J Vestib Res 8:299-312.

Huerta MF, Krubitzer LA, Kaas JH (1986) Frontal eye field as defined by intracortical microstimulation in squirrel monkeys, owl monkeys and macaque monkeys: 1. Subcortical connections. J Comp Neurol 253:415-439.

Hutchison WD, Lühn MA, Schmidt RF (1992) Knee joint input into the peripheral region of the ventral posterior lateral nucleus of cat thalamus. J Neurophysiol 67:1092-1104.

Kalil K (1981) Projections of the cerebellar and dorsal column nuclei upon the thalamus of the rhesus monkey. J Comp Neurol 195:25-50.

Klam F, Graf W (2003) Discrimination between active and passive head 
movements by macaque ventral and medial intraparietal cortex neurons. J Physiol (Lond) 574:367-386.

Kotchabhakdi N, Rinvik E, Walberg F, Yingchareon K (1980) The vestibulothalamic projections in the cat studied by retrograde axonal transport of horseradish peroxidase. Exp Brain Res 40:405-418.

Lang W, Büttner-Ennever JA, Büttner U (1979) Vestibular projections to the monkey thalamus: an autoradiographic study. Brain Res 177:3-17.

Lewis JW, Van Essen DC (2000) Corticocortical connections of visual, sensorimotor, and multimodal processing areas in the parietal lobe of the macaque monkey. J Comp Neurol 428:112-137.

Liedgren SR, Milne AC, Schwarz DW, Tomlinson RD (1976) Representation of vestibular afferents in somatosensory thalamic nuclei of the squirrel monkey (Saimiri sciureus). J Neurophysiol 39:601-612.

Macchi G, Jones EG (1997) Toward an agreement on terminology of nuclear and subnuclear divisions in the motor thalamus. J Neurosurg 86:670-685.

Maciewicz R, Phipps BS, Bry J, Highstein SM (1982) The vestibulothalamic pathway: contribution of the ascending tract of Deiters. Brain Res 252:1-11.

Maendly R, Rüegg DG, Wieseddanger M, Wiesendanger R, Lagowska J, Hess B (1981) Thalamic relay for group I muscle afferents of forelimb nerves in the monkey. J Neurophysiol 46:901-917.

Magnin M, Fuchs AF (1977) Discharge properties of neurons in the monkey thalamus tested with angular acceleration, eye movement and visual stimuli. Exp Brain Res 28:293-299.

Matsuo S, Hosogai M, Nakao S (1994) Ascending projections of posterior cannal-activated excitatory and inhibitory secondary vestibular neurons to the mesodiencephalon in cats. Exp Brain Res 100:7-17.

Meng H, Angelaki DE (2006) Neural correlates of the dependence of compensatory eye movements during translation on target distance and eccentricity. J Neurophysiol 95:2530-2540.

Meng H, Bai RS, Sato H, Imagawa M, Sasaki M, Uchino Y (2001) Otolithactivated vestibulothalamic neurons in cats. Exp Brain Res 141:415-424.

Meng H, Green AM, Dickman JD, Angelaki DE (2005) Pursuit-vestibular interactions in brain stem neurons during rotation and translation. J Neurophysiol 93:3418-3433.

Meng H, May PM, Dickman JD, Angelaki DE (2006) Neural response properties and anatomical origins of vestibular responses in the primate thalamus. Soc Neurosci Abstr 32:244.13.

Mergner T, Siebold C, Schweigart G, Becker W (1991) Human perception of horizontal trunk and head rotation in space during vestibular and neck stimulation. Exp Brain Res 85:389-404.

Middleton FA, Strick PL (1997) Cerebellar output channels. Int Rev Neurobiol 41:61-82.

Nagata S (1986) The vestibulothalamic connections in the rat: a morphological analysis using wheat germ agglutinin-horseradish peroxidase. Brain Res 376:57-70.

Nakano K, Kohno M, Hasegawa Y, Tokushige A (1985) Cortical and brainstem afferents to the ventral thalamic nuclei of the cat demonstrated by retrograde axonal transport of horseradish peroxidase. J Comp Neurol 231:102-120.

Odkvist LM, Schwarz DW, Fredrickson JM, Hassler R (1974) Projection of the vestibular nerve to the area $3 \mathrm{a}$ arm field in the squirrel monkey (Saimiri sciureus). Exp Brain Res 21:97-105.

Okada T, Grunfeld E, Shallo-Hoffmann J, Bronstein AM (1999) Vestibular perception of angular velocity in normal subjects and in patients with congenital nystagmus. Brain 122:1293-1303.

Olszewski J (1952) The thalamus of the Macaca mulatta: an atlas for use with the stereotaxic instrument, pp 54-70. Basel: Karger.

Olucha F, Martinez-Garcia F, Lopez-Garcia C (1985) A new stabilizing agent for the tetramethyl benzidine (TMB) reaction product in the histochemical detection of horseradish peroxidase. J Neurosci Methods 13:131-138.

Page WK, Duffy CJ (2003) Heading representation in MST: sensory interactions and population encoding. J Neurophysiol 89:1994-2013.

Paxinos G, Huang X-F, Toga AW (2000) The rhesus monkey brain in stereotaxic coordinates. San Diego: Academic.

Perkins E, Warren S, Lin RC-S, May PJ (2006) Projections of somatosensory cortex and frontal eye fields onto incertotectal neurons in the cat. Anat Rec 288A:1310-1329.
Raphan T, Matsuo V, Cohen B (1979) Velocity storage in the vestibuloocular reflex arc (VOR). Exp Brain Res 35:229-248.

Sakai ST, Inase MI, Tanji J (1996) Comparison of cerebellothalamic and pallidothalamic projections in the monkey (Macaca fuscata): a double anterograde labeling study. J Comp Neurol 386:215-228.

Saleem KS, Logothetis NK (2007) A combined MRI and histology atlas of the rhesus monkey brain in stereotaxic coordinates. San Diego: Academic.

Schwarz DW, Fredrickson JM (1971a) Tactile direction sensitivity of area 2 oral neurons in the rhesus monkey cortex. Brain Res 27:397-401.

Schwarz DW, Fredrickson JM (1971b) Rhesus monkey vestibular cortex: a bimodal primary projection field. Science 172:280-281.

Shaikh AG, Meng H, Angelaki DE (2004) Multiple reference frames for motion in the primate cerebellum. J Neurosci 24:4491-4497.

Shaikh AG, Ghasia FF, Dickman JD, Angelaki DE (2005a) Properties of cerebellar fastigial neurons during translation, rotation, and eye movements. J Neurophysiol 93:853-863.

Shaikh AG, Green AM, Ghasia FF, Newlands SD, Dickman JD, Angelaki DE (2005b) Sensory convergence solves a motion ambiguity problem. Curr Biol 15:1657-1662.

Shiroyama T, Kayahara T, Yasui Y, Nomura J, Nakano K (1995) The vestibular nuclei of the rat project to the lateral part of the thalamic parafascicular nucleus (centromedian nucleus in primates). Brain Res 704:130-134.

Shiroyama T, Kayahara T, Yasui Y, Nomura J, Nakano K (1999) Projections of the vestibular nuclei to the thalamus in the rat: a Phaseolus vulgaris leurcoagglutinin study. J Comp Neurol 407:318-332.

Siebold C, Glonti L, Glasauer S, Büttner U (1997) Rostral fastigial nucleus activity in the alert monkey during three-dimensional passive head movements. J Neurophysiol 77:1432-1446.

Siebold C, Kleine JF, Glonti L, Tchelidze T, Büttner U (1999) Fastigial nucleus activity during different frequencies and orientations of vertical vestibular stimulation in the monkey. J Neurophysiol 82:34-41.

Smith MA, Majaj NJ, Movshon JA (2005) Dynamics of motion signaling by neurons in macaque area MT. Nat Neurosci 8:220-228.

Stanton GB (1980) Topographical organization of ascending cerebellar projections from the dentate and interposed nuclei in Macaca mulatta: an anterograde degeneration study. J Comp Neurol 190:699-731.

Stanton GB, Bruce CJ, Goldberg ME (1995) Topography of projections to posterior cortical areas from the macaque frontal eye fields. J Comp Neurol 353:291-305.

Steriade M, Jones EG, McCormick DA (1997) Thalamic organization and chemical anatomy. In: Thalamus, Vol I. Organization and function, pp 31-108. Amsterdam: Elsevier.

Suzuki Y, Buttner-Ennever JA, Straumann D, Hepp K, Hess BJ, Henn V (1995) Deficits in torsional and vertical rapid eye movements and shift of Listing's plane after uni- and bilateral lesions of the rostral interstitial nucleus of the medial longitudinal fasciculus. Exp Brain Res 106:215-232.

Takahashi K, Gu Y, May PJ, Newlands SD, DeAngelis GC, Angelaki DE (2007) Multi-modal coding of three-dimensional rotation and translation in area MSTd: comparison of visual and vestibular sensitivity. J Neurosci 27:9742-9756.

Thach WT (1987) Cerebellar inputs to motor cortex. Ciba Found Symp 132:201-220.

Waespe W, Henn V (1977) Neuronal activity in the vestibular nuclei of the alert monkey during vestibular and optokinetic stimulation. Exp Brain Res 27:523-538.

Wong-Riley M (1979) Changes in the visual system of monocularly sutured or enucleated cats demonstrable with cytochrome oxidase histochemistry. Brain Res 171:11-28.

Yakusheva TA, Shaikh AG, Green AM, Blazquez PM, Dickman JD, Angelaki DE (2007) Purkinje cells in posterior cerebellar vermis encode motion in an inertial reference frame. Neuron 54:973-985.

Yakushin SB, Raphan T, Cohen B (2006) Spatial properties of central vestibular neurons. J Neurophysiol 95:464-478.

Zhou W, Tang BF, King WM (2001) Responses of rostral fastigial neurons to linear acceleration in an alert monkey. Exp Brain Res 139:111-115.

Zhou W, Tang BF, Newlands SD, King WM (2006) Responses of monkey vestibular-only neurons to translation and angular rotation. J Neurophysiol 96:2915-2930. 